\title{
Primary Calvarial Meningioma
}

\author{
Saleh Rasras ${ }^{1}$; Alireza Teimouri ${ }^{1{ }^{1}}$; Fardin Ranjbar $^{1}$; Iman Zaeim ${ }^{1}$; Mohammad Ardeshiri ${ }^{1}$ \\ ${ }^{1}$ Neurosurgery Department, Faculty of Medicine, Golestan Hospital, Ahvaz Jundishapur University of Medical Sciences, Ahvaz, IR Iran \\ ${ }^{*}$ Corresponding author: Alireza Teimouri, Neurosurgery Department, Faculty of Medicine, Golestan Hospital, Ahvaz Jundishapur University of Medical Sciences, Ahvaz, IR Iran. Tel/ \\ Fax:+98-6113743032, E-mail: dr.alirezateimouri@yahoo.com
}

Received: January 2, 2015; Revised: April 5, 2015; Accepted: April 13, 2015

\begin{abstract}
Introduction: Although meningioma is the most common non-glial tumor of intracranial space, primary extra cranial meningioma is rare and comprises less than $2 \%$ of all meningioma.

Case Presentation: We report a case of slowly progressing extracranial meningioma that was presented in a young adult woman. The tumor was asymptomatic but large enough to cause cosmetic discomfort. Patient underwent successful and complete surgical resection of her tumor and eventually fully recovered.

Conclusions: Primary Extracranial Meningiomas (PEMs) without intracranial origin are very rare and because of their slow growing nature are initially managed by primary care physicians.
\end{abstract}

Keywords: Meningioma; Tumor; Physicians

\section{Introduction}

Although meningioma is one of the most common tumors encountered in neurosurgery patients, primary calvarias meningioma are very uncommon (1). Calvarial meningioma is a variety of extracranial meningioma that originates from meningothelial cells and primarily invades the bone tissue and results in hyperostosis; however, diffuse and widespread bone thickening is rare. Such meningioma is rare unlike the more commonly seen intracranial meningioma and its clinical presentation differs based on its sizes and location (2). They present themselves as a slowly growing scalp mass that are usually pain free and more commonly seen in periorbital or frontoparietal regions (3). Trauma has been proposed as a cause of these kind of tumors where meningothelial cells trap into the suture lines or a fracture and consequently grow to become a tumor (3). Most tumors are histologically benign and in case of malignancy, distant metastasis are rare. Its male to female ratio is 1:1 (4).

\section{Case Presentation}

A 19-year-old female presented with a slow growing mass in her occipital region. Mass was growing for the past 7 years; however, it was pain free and covered by her hair, so she did not seek any medical attention. At the time of presentation the tumor had grown large enough to cause cosmetic and health concerns for her. She did not give any history of trauma, skull fracture, previous tumors, and any medical issues requiring hospitalization. She also did not give any family history of radiation, cancer, or congenital disease. Tumor had not caused any mental or physical growth disruption and her physical exam apart from the occipital mass was normal. Occipital mass was nontender, measuring $10 \mathrm{~cm} \times 10 \mathrm{~cm}$ with no superficial scarring. The thickness of the mass at its highest part was $4 \mathrm{~cm}$. No other positive physical findings were observed and neurological exam was completely benign. Laboratory tests all came back normal. CT scan and MRI reported an occipital hyperostosis with $10 \mathrm{~cm} \times$ $11 \mathrm{~cm} \times 4 \mathrm{~cm}$ tumor that had crossed the midline without any intracranial involvement (Figure 1).

Patient with the primary diagnosis of fibrosacroma was taken to the operating room and under general anesthesia, tumor was completely excised. No dural involvement or injury was observed or occurred during surgery.

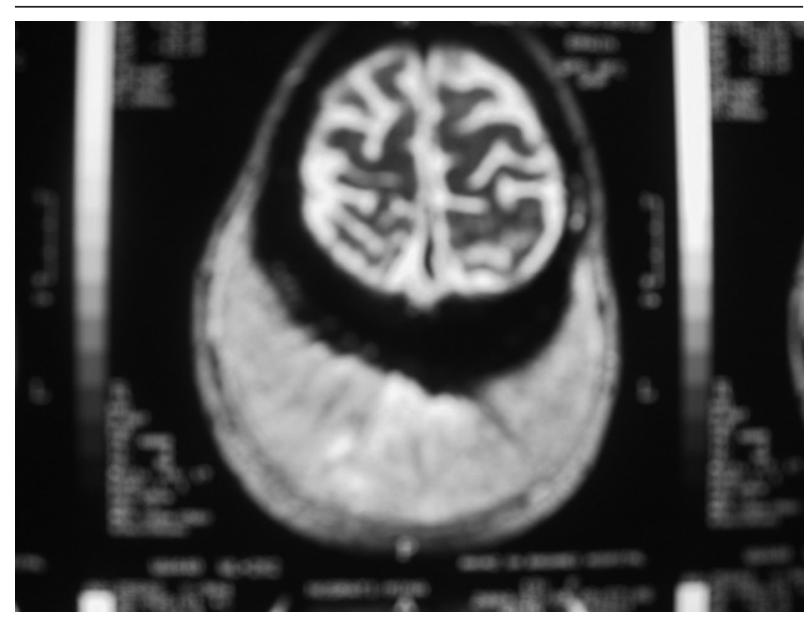

Figure 1. Preoperative Axial View T-2 MRI With Tumor Crossing Midline

Copyright (C) 2015, Ahvaz Jundishapur University of Medical Sciences. This is an open-access article distributed under the terms of the Creative Commons Attribution-NonCommercial 4.0 International License (http://creativecommons.org/licenses/by-nc/4.0/) which permits copy and redistribute the material just in noncommercial usages, provided the original work is properly cited. 
Apart from some bleeding during the surgery due to hypervascularity of the tumor, there was no injury to the brain tissue or cerebral venous sinus (Figure 2). Tumor was completely excised with wide resection of tumor edges and removal of adjacent dura. Patient had an uneventful postoperative period and discharged on the fourth hospital day. Microscopic Pathology of tumor confirms meningioma. Seven years postoperative follow up proved no sign of the tumor or no sensory neural deficit (Figures 3 - 6).

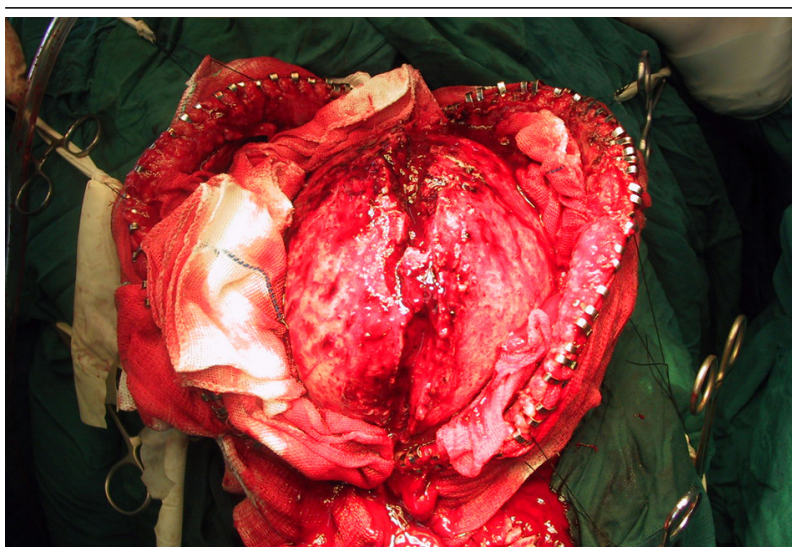

Figure 2. Intraoperative View

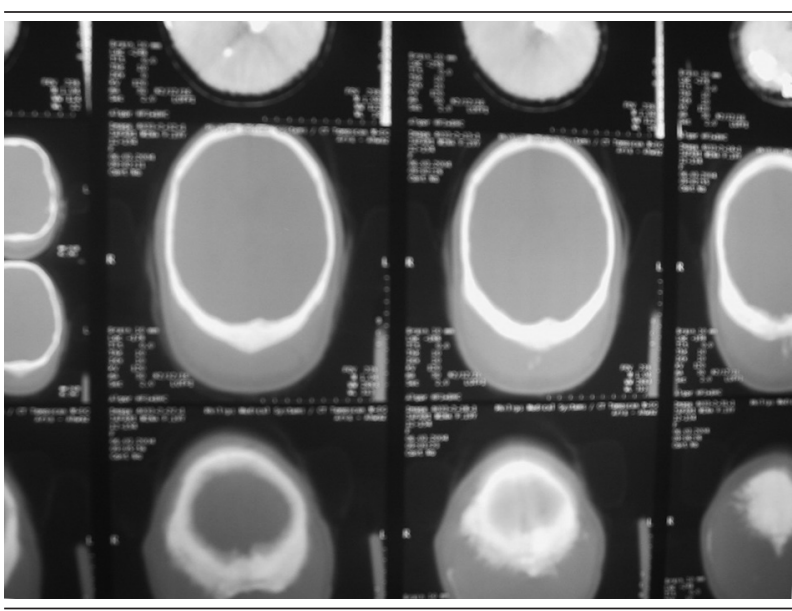

Figure 3. Postoperative Axial CT SCAN, Show Total Removal of Tumor

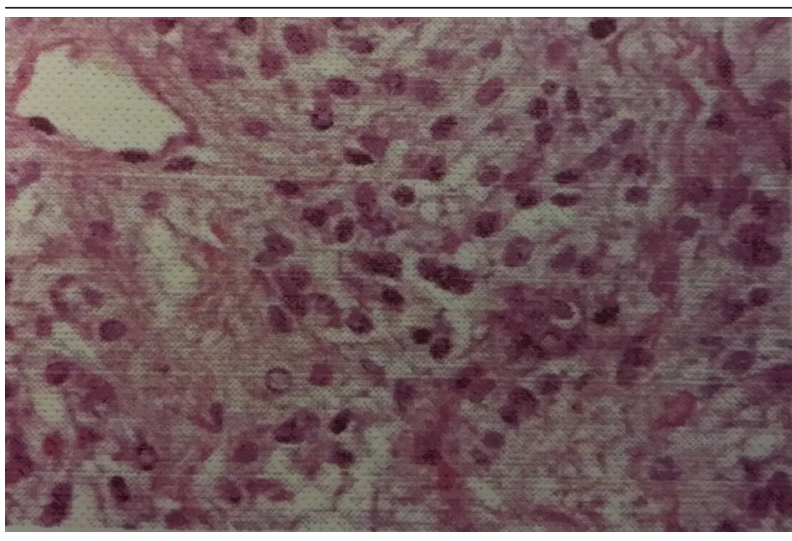

Figure 4. Microscopic Pathology of Patient

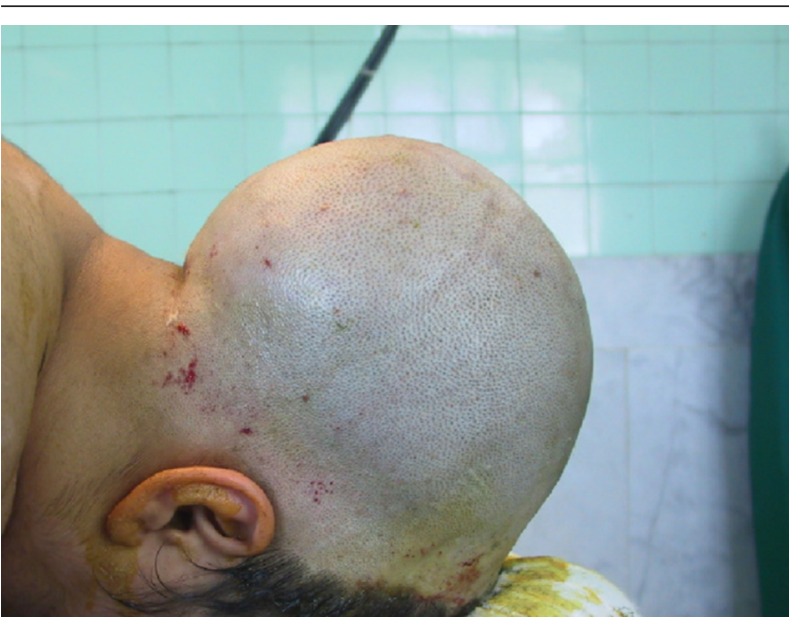

Figure 5. Preoperative View of Patient

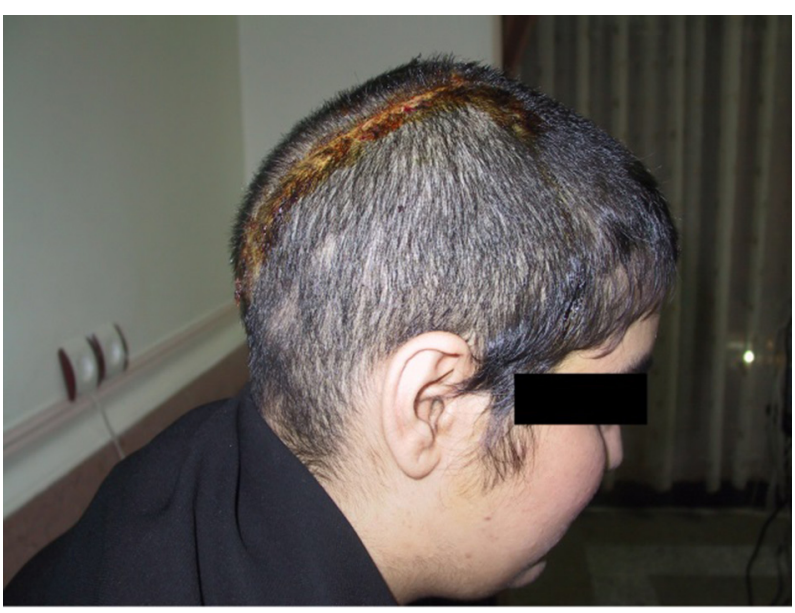

Figure 6. Postoperative View of Patient

\section{Discussion}

As explained before, primary extra dural meningiomas are extremely rare. In reviewing the literature, we found 6 other reports of occipital meningioma but none were as extensive as the case that is reported here. Increased intracranial pressure is usually a complication associated with PEMs that is caused by dural thickening and hyperostosis. It might also result from occlusion of dural sinus and interruption of cerebrospinal fluid clearance (5). Extradural meningiomas are usually benign and slow growing but unlike intracranial meningioma they have higher tendency to become invasive (11\% vs. $3 \%)(2,6)$. Meningioma presenting with scalp swelling, osteolytic skull lesions, and extracranial soft-tissue masses are found to be more aggressive (7). Meningioma is histologically categorized into different subtypes as meningothelial (syncytial), fibrous (fibroblastic), psammomatous, angiomatous (angioblastic), and transitional (mixed) (4). The angioblastic type may have a mesenchymal non-menin- 
gothelial origin and also known as hemangiopericytoma of the meninges (8). Most extracranial meningioma of the paranasal sinuses have been syncytial (9). Imaging studies, particularly CT scan can be helpful to narrow down the diagnosis. All primary metastatic soft tissue, or bone neoplasm have to be considered. However, when a slow growing painless mass was observed, PEM should be considered.

\section{Acknowledgements}

Our special thanks go to members of Golestan Hospital Clinical Development Research Unit and Molook Salemzadeh for helping us in submission and submission consultancy.

\section{References}

1. Leestma JE. Brain tumors. Am JPathol. 1980;100(1):239-316.
2. Lang FF, Macdonald OK, Fuller GN, DeMonte F. Primary extradural meningiomas: a report on nine cases and review of the literature from the era of computerized tomography scanning. Neurosurg. 2000;93(6):940-50.

3. Azar-Kia B, Sarwar M, Marc JA, Schechter MM. Intraosseous meningioma. Neuroradiology. 1974;6(5):246-53.

4. P. Kleihues P, Burger PC, Scheithauer BW. Histological Typing of Tumors of the Central Nervous System. International Histological Classification of Tumors.University Hospital, Zurich, Switzerland: Springer; 1993.

5. Lee HY, Prager J, Hahn Y, Ramsey RG. Intraosseous meningioma: CT and MR appearance. J Comput Assist Tomogr. 1992;16(6):1000-1.

6. Shuangshoti S, Netsky MG, Fitz-Hugh GS. Parapharyngeal meningioma with special reference to cell of origin. Ann Otol Rhinol Laryngol.1971;80(3):464-73.

7. Tokgoz N, Oner YA, Kaymaz M, Ucar M, Yilmaz G, Tali TE. Primary intraosseous meningioma: CT and MRI appearance. AJNR Am J Neuroradiol. 2005;26(8):2053-6.

8. Gerhard FW. Skull Base Surgery First International Skull Base Congress, Hannover 1992. In: Sammie M editor. Morphology and biology of meningioma.. Basel: Karger;1992. pp.161-4.

9. Ho KL. Primary meningioma of the nasal cavity and paranasal sinuses. Cancer. 1980;46(6):1442-7. 